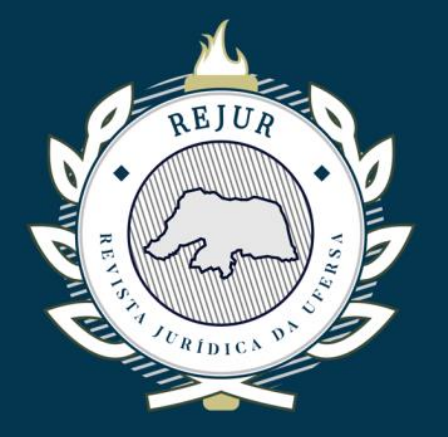

\title{
SEGURANÇA AÉREA E ABATE DE AVIÕES:
} ASPECTOS JURÍDICO-FUNDAMENTAIS

AIR SAFETY AND AIRCRAFT ABATE: LEGAL AND FUNDAMENTAL ISSUES

\section{LEONARDO SIMCHEN TREVISAN*}

\section{RESUMO}

Face à preocupação com o uso de meios de transporte aéreo para o cometimento de delitos, diferentes países passaram a prever legalmente a medida de abate de aeronaves suspeitas. Semelhante expediente, todavia, entra em conflito com direitos fundamentais, em especial com o direito à vida e a proteção da dignidade humana das pessoas a bordo. Isso posto, o presente trabalho busca, em um primeiro momento, analisar a decisão do Tribunal Constitucional Federal da Alemanha a respeito do abate de aviões (BVerfGE 115, 118), descrevendo seus fundamentos e explicando-a a partir da teoria da ponderação. A experiência alemã serve como ponto de referência para que, em um segundo momento, seja exposta a legislação brasileira a respeito do tema, com a necessária indagação acerca de sua constitucionalidade.

Palavras-chave: abate de aeronaves; segurança aérea; direito à vida; dignidade humana.

\section{ABSTRACT}

In view of the concerns about the use of airplanes in criminal activities, different countries have legally authorized the use of military force against suspicious aircraft. This authorization, however, leads to a conflict among principles, namely, the fundamental rights to life and human dignity of the passengers on board. This paper seeks to analyze the decision of the Federal Constitutional Court of Germany regarding the authorization to shoot down airplanes (BVerfGE $115,118)$, exposing its reasoning and explaining it by the theory of balancing. The German experience serves as a point of reference to the analysis of Brazilian legislation on that subject, with the necessary inquiries about its constitutionality.

Keywords: shoot down aircraft; aviation safety; right to life; human dignity.

\footnotetext{
* Doutorando em Direito pela Universidade Federal do Rio Grande do Sul (UFRGS). Mestre em Direito pela UFGRS. leonardo_tapes@hotmail.com
} 


\section{SUMÁRIO}

INTRODUÇÃO; 1 A DECISÃO DO TRIBUNAL CONSTITUCIONAL FEDERAL DA ALEMANHA ACERCA DO ABATE DE AVIÕES: BVERFGE 115, 118; 1.1 FUNDAMENTOS DA BVERFGE 115, 118; 1.1 .1

Considerações prévias; 1.1.2 Fundamentação propriamente dita; 1.2 A BVERFGE 115, 118 À LUZ DA TEORIA DA PONDERAÇÃO; 1.2.1 A distinção entre regras e princípios; 1.2.2 Princípios, proporcionalidade e ponderação; 1.2.2.1 Duas leis da ponderação; 1.2.2.2 A fórmula peso; 1.2.2.3 $A$ insegurança empírica como fator determinante para o juízo de ponderação no caso do abate de aviões; 20 ABATE DE AVIÕES NO BRASIL; 2.1 LEGISLAÇÃO BRASILEIRA SOBRE ABATE DE AVIÕES; 2.2 É CONSTITUCIONAL A PERMISSÃO PARA O ABATE DE AVIÕES NO ESPAÇO AÉREO BRASILEIRO?; CONCLUSÃO

\section{INTRODUÇÃO}

Várias foram as consequências do ataque terrorista de 11 de setembro de 2001 nos Estados Unidos, provavelmente o mais significativo fato histórico deste século. Seus efeitos geopolíticos, entre os quais a gigantesca perda de vidas humanas em operações militares no Oriente Médio, foram até mais conspícuos e aterradores que o ataque em si. Menos conhecidos, todavia, são os efeitos jurídicos daquele ataque. A forma pela qual o ato terrorista foi executado, envolvendo o sequestro e a destruição premeditada de aeronaves civis de grande porte, provocou, em nível mundial, debates acerca da segurança do tráfego aéreo, os quais, naturalmente, levaram a inovações no plano jurídico de diversos países.

Um exemplo disso foi a promulgação, no ano de 2005, da Lei de Segurança Aérea pelo parlamento federal alemão. Entre as inovações trazidas por essa lei, todavia, estavam alguns dispositivos extremamente polêmicos, os quais tornavam juridicamente viável o abate de aeronaves civis que presumivelmente estivessem sendo utilizadas em atos terroristas. Essa discussão, que envolvia a garantia da segurança aérea em conflito com a provável perda de vidas inocentes, chegou ao Tribunal Constitucional Federal da Alemanha, onde, no ano de 2006, a medida em questão foi declarada inconstitucional.

No Brasil, ao contrário do que se verificou na maior parte do mundo, as discussões sobre abate de aeronaves já haviam começado no final da década de 1990, em razão da necessidade que o país enfrentava de combater o tráfico internacional de drogas realizado por pequenos aviões nas fronteiras com os seus vizinhos da América do Sul. Em face dos acontecimentos que se desenrolaram nos anos seguintes ao redor do mundo, a lei que inicialmente havia sido promulgada com esse objetivo passou a ser também um instrumento de enfrentamento ao terrorismo.

Diante disso, o presente trabalho tenciona, em um primeiro momento, expor a fundamentação da decisão adotada pelo Tribunal Constitucional Federal da Alemanha que tornou inconstitucional o dispositivo da Lei de Segurança Aérea sobre a autorização para o abate de aeronaves civis, analisando-a dogmaticamente à luz da teoria da ponderação. Em um segundo momento, será abordada a legislação brasileira relativa à possibilidade de abate de aviões e, com inspiração na experiência alemã, será discutida a sua compatibilidade com a ordem constitucional adotada pela República Federativa do Brasil. 


\section{A DECISÃO DO TRIBUNAL CONSTITUCIONAL FEDERAL DA ALEMANHA ACERCA DO ABATE DE AVIÕES: BVERFGE 115, 118}

\subsection{FUNDAMENTOS DA BVERFGE 115, 118}

\subsubsection{Considerações prévias}

Decisão proferida pelo 1 o Senado do Tribunal Constitucional Federal em 15 de fevereiro de 2006. A decisão foi proferida em sede de recurso constitucional, o qual havia sido interposto contra um dispositivo da Lei de Segurança Aérea (Luftsicherheitsgesetz), o § 14, alínea 3, que autorizava a força aérea alemã a abrir fogo contra aviões de passageiros que supostamente estariam sendo utilizados para ataques terroristas e, portanto, seriam transformados em armas dirigidas contra a vida de outras pessoas além daquelas que se encontravam no interior da aeronave. ${ }^{1}$

A decisão começa descrevendo alguns fatos que antecederam a promulgação da Lei de Segurança Aérea, especificamente os ataques de 11 de setembro de 2001, nos Estados Unidos, que deixaram mais de três mil mortos, e também um incidente ocorrido em Frankfurt am Main no dia 05 de janeiro de 2003, quando um homem chamado Franz StefanStrammbach sequestrou um avião e, voando em círculos sobre os arranha-céus da cidade, ameaçou jogar a aeronave contra o prédio do Banco Central Europeu. Esse incidente terminou sem vítimas, mas chamou a atenção das autoridades alemãs para os problemas relacionados à segurança do tráfego aéreo. ${ }^{2}$

Como consequência desse novo tipo de ataque terrorista, desencadeou-se uma série de medidas ao redor do mundo com o objetivo de elevar a segurança da aviação civil. No âmbito da União Europeia, foi editado o Regulamento n.o 2.320 (promulgado em 2002 e substancialmente alterado em 2004), que estabeleceu disposições comuns de segurança para a aviação civil no âmbito dos Estados-membros da comunidade. Entre as medidas de segurança introduzidas por esse Regulamento estavam exigências relativas à vigilância nos aeroportos (especialmente nas áreas dos aeroportos que são acessíveis ao público em geral), prescrições acerca de controle dos passageiros e de suas bagagens antes do embarque, determinações sobre a contratação e o treinamento de pessoal de bordo, entre outras estipulações. $^{3}$

$\mathrm{Na}$ Alemanha, esse recrudescimento das medidas de segurança aérea foi, do ponto de vista jurídico, cristalizado na Lei de Segurança Aérea, de 11 de janeiro de 2005. O primeiro parágrafo da referida Lei deixa claro esse intento quando diz que o seu objetivo é a proteção da aviação civil contra sequestro de aeronaves, atos de sabotagem e atentados terroristas. ${ }^{4} \mathrm{~A}$

\footnotetext{
${ }^{1}$ BVerfGE 115, 118.

2 BVerfGE 115, 118.

${ }^{3}$ BVerfGE 115, 118.

${ }^{4}$ Eis o texto do dispositivo mencionado: “§ 1 Objetivo: Essa lei serve para a proteção contra ataques à segurança do tráfego aéreo civil, particularmente contra sequestros de aviões, atos de sabotagem e atentados terroristas".
} 
seção mais polêmica da Lei de Segurança Aérea é a terceira, intitulada "Suporte e Assistência das Forças Armadas", que compreende os parágrafos 13, 14 e 15. No $\S 13$, alínea 1, a Lei estabelece que, na existência de fatos que permitam concluir que uma ação foi levada a efeito durante o voo de modo a dar margem à ocorrência de um desastre aéreo, é possível, além da força policial, mobilizar as forças armadas na tentativa de conter esse perigo. ${ }^{5} \mathrm{O} \S 14$, alínea 1, estabelece que, para evitar esse tipo de desastre, as forças armadas podem obrigar o avião a abandonar a sua rota, podem coagi-lo a aterrissar, podem ameaçá-lo com o emprego das armas e podem disparar tiros de advertência. ${ }^{6}$ De acordo com a alínea 2 desse parágrafo, exige-se que o princípio da proporcionalidade seja observado na escolha dessas medidas. ${ }^{7}$ Por sua vez, a alínea 3 desse parágrafo estabelece que, uma vez esgotadas as medidas menos gravosas, é possível uma agressão à aeronave suspeita, desde que as circunstâncias permitam concluir que esse avião está sendo utilizado como arma contra a vida de outras pessoas e, ao mesmo tempo, que abrir fogo contra ele é a única forma de evitar esse resultado. ${ }^{8} \mathrm{~A}$ alínea seguinte desse parágrafo estabelece que a ordem para a agressão ao avião suspeito deve

No original: „§ 1 Zweck: Dieses Gesetz dient dem Schutz vor Angriffen auf die Sicherheit des Zivilen Luftverkehrs, insbesondere vor Flugzeugentführungen, Sabotageakten und terroristischen Anschlägen."

${ }^{5}$ Eis o texto do dispositivo mencionado: "§ 13 Decisão do Governo Federal: (1) Existindo, devido a um incidente aéreo significativo, fatos que, no quadro de defesa contra perigos, justificam a suposição de que um desastre particularmente grave, nos termos do artigo 35, alínea 2, frase 2 ou alínea 3 da Lei Fundamental, é iminente, podem as forças armadas, enquanto for necessário para o combate eficaz, ser mobilizadas para o suporte das forças policiais dos estados no espaço aéreo para a prevenção desse desastre." No original: „§ 13 Entscheidung der Bundesregierung: (1) Liegen auf Grund eines erheblichen Luftzwischenfalls Tatsachen vor, die im Rahmen der Gefahrenabwehr die Annahme begründen, dass ein besonders schwerer Unglücksfall nach Artikel 35 Abs. 2 Satz 2 oder Abs. 3 des Grundgesetzes bevorsteht, können die Streitkräfte, soweit es zur wirksamen Bekämpfung erforderlich ist, zur Unterstützung der Polizeikräfte der Länder im Luftraum zur Verhinderung dieses Unglücksfalles eingesetzt werden."

${ }^{6}$ Eis o texto do dispositivo mencionado: “§ 14 Medidas de Mobilização, Competência para a Ordem: (1) Para a prevenção da ocorrência de um desastre particularmente grave, podem as forças armadas no espaço aéreo desviar aviões, obrigá-los à aterrissagem, ameaçá-los com o emprego de violência armada ou disparar tiros de advertência." No original: „§ 14 Einsatzmaßnahmen, Anordnungsbefugnis: (1) Zur Verhinderung des Eintritts eines besonders schweren Unglücksfalles dürfen die Streitkräfte im Luftraum Luftfahrzeuge abdrängen, zur Landung zwingen, den Einsatz von Waffengewalt androhen oder Warnschüsse abgeben."

${ }^{7}$ Eis o texto do dispositivo mencionado: “§ 14 [...] (2) Entre várias medidas possíveis, deve-se escolher aquela que presumivelmente menos prejudique o indivíduo e a coletividade. A medida só pode ser levada a efeito enquanto e na medida que o seu objetivo o exige. Ela não pode levar a uma desvantagem que seja reconhecidamente desproporcional em relação ao resultado desejado.” No original: „\$ 14 [...] (2) Von mehreren möglichen Maßnahmen ist diejenige auszuwählen, die den Einzelnen und die Allgemeinheit voraussichtlich am wenigsten beeinträchtigt. Die Maßnahme darf nur so lange und so weit durchgeführt werden, wie ihr Zweck es erfordert. Sie darf nicht zu einem Nachteil führen, der zu dem erstrebten Erfolg erkennbar außer Verhältnis steht." ${ }^{8}$ Eis o texto do dispositivo mencionado: "§ 14 [...] (3) A ação direta com a força das armas só é admissível quando, a partir das circunstâncias, depreende-se que a aeronave deverá ser utilizada contra a vida de pessoas e esse é o único meio de defesa contra esse perigo atual." No original: „£ 14 [...] (3) Die unmittelbare Einwirkung mit Waffengewalt ist nur zulässig, wenn nach den Umständen davon auszugehen ist, dass das Luftfahrzeug gegen das Leben von Menschen eingesetzt werden soll, und sie das einzige Mittel zur Abwehr dieser gegenwärtigen Gefahr ist." 
partir do ministro da defesa ou, em substituição a ele, do seu representante junto ao governo federal. ${ }^{9} 10$

O recurso constitucional que deu origem à decisão em pauta dirige-se imediatamente contra o § 14, alínea 3 da Lei de Segurança Aérea. O recorrente argumenta que a autorização de abate de aeronaves civis, como prevista naquele dispositivo, viola os seus direitos garantidos no artigo 1, alínea 1 da Lei Fundamental (que trata da dignidade humana) ${ }^{11}$ e no artigo 2, alínea 2 da mesma Lei Fundamental (que trata dos direitos à vida e à integridade física), ${ }^{12}$ complementados pelo artigo 19, alínea 2 da Lei Fundamental, que garante que nenhum direito fundamental poderá ser violado em sua essência. ${ }^{13} \mathrm{O}$ principal argumento trazido no recurso é o de que essa possibilidade do abate de um avião de passageiros transforma as pessoas que estão dentro do avião (e que, portanto, são tão vítimas da situação quanto aquelas que serão potencialmente afetadas em terra pela utilização desse avião como arma) em mero objeto de uma ação estatal. Essas pessoas, de acordo com o recurso, seriam duplamente brutalizadas, primeiro como vítimas de um crime de terrorismo e depois como alvo de uma agressão estatal premeditada, agressão essa cuja possibilidade decorre do exercício de um poder discricionário de uma autoridade específica, o ministro da defesa, que pode ordenar o abate do avião sob o pressuposto extremamente vago das circunstâncias do caso. Além disso, o recorrente sustenta que o Estado não pode tentar proteger uma maioria de cidadãos através do extermínio premeditado de uma minoria (no caso, as pessoas que estão a bordo do avião). Uma ponderação de vida contra vida, determinada pela quantidade de pessoas que estão de um lado e de outro, seria totalmente incompatível com a dignidade humana; o Estado não pode simplesmente matar um determinado número de pessoas com a justificativa de que ele espera, com essa ação, salvar a vida de outras que estão em maior número. ${ }^{14}$

Um argumento secundário do recorrente diz respeito à impossibilidade constitucional de utilização das forças armadas para o abate de aviões de passageiros. $O$ artigo 87 a, alínea 2 da Lei Fundamental estabelece que as forças armadas alemãs, fora da sua função de defesa, somente podem intervir quando a Lei Fundamental expressamente autoriza que

\footnotetext{
${ }^{9}$ Eis o texto do dispositivo mencionado: "§ 14 [...] (4) A medida da alínea 3 pode ordenar somente o ministro federal da defesa, ou, em caso de substituição, o membro do governo federal autorizado à sua substituição." No original: „§ 14 [...] (4) Die Maßnahme nach Absatz 3 kann nur der Bundesminister der Verteidigung oder im Vertretungsfall das zu seiner Vertretung berechtigte Mitglied der Bundesregierung anordnen."

10 BVerfGE 115, 118.

${ }^{11}$ Eis o texto do dispositivo mencionado: “Artigo 1 (1) A dignidade humana é intangível. Considerá-la e protegêla é obrigação de todo poder estatal." No original: „Artikel 1 (1) Die Würde des Menschen ist unantastbar. Sie zu achten und zu schützen ist Verpflichtung aller staatlichen Gewalt."

12 Eis o texto do dispositivo mencionado: "Artigo 2 (2) Todos têm o direito à vida e à integridade corporal. A liberdade da pessoa é inviolável. Nesses direitos pode-se somente intervir com base em uma lei." No original: "Artikel 2 (2) Jeder hat das Recht auf Leben und körperliche Unversehrtheit. Die Freiheit der Person ist unverletzlich. In diese Rechte darf nur auf Grund eines Gesetzes eingegriffen werden."

${ }^{13}$ Eis o texto do dispositivo mencionado: "Artigo 19 (2) Em nenhum caso pode um direito fundamental ser violado em seu conteúdo essencial." No original: "Artikel 19 (2) In keinem Falle darf ein Grundrecht in seinem Wesensgehalt angetastet werden."

14 BVerfGE 115, 118.
} 
elas o façam. ${ }^{15}$ Segundo o recorrente, os pressupostos constitucionais para essa intervenção não existem no caso do abate de aviões. ${ }^{16}$

A respeito desse recurso constitucional, várias manifestações foram apresentadas. Entre elas estavam a do parlamento federal e a do governo federal.

O parlamento federal defendeu a constitucionalidade do dispositivo atacado. De acordo com sua manifestação, a possibilidade de abate de aviões prevista na Lei de Segurança Aérea não viola a dignidade humana dos passageiros do avião, na medida em que a ação estatal é dirigida imediatamente contra aqueles que tomaram o avião em seu poder e planejam não apenas matar as pessoas que estão a bordo, mas também utilizar a aeronave como instrumento para a morte de outras pessoas em terra. Quanto ao direito à vida dos passageiros, tampouco pode ser reconhecida qualquer violação, pois o próprio artigo 2, alínea 2 da Lei Fundamental possibilita que o direito fundamental à vida seja restringido com base em lei. No caso, essa restrição seria necessária para o caso excepcional de um ataque a uma aeronave, através do qual é razoável supor que, em comparação com o número reduzido de pessoas que estão a bordo, a vida de um número maior de indivíduos em terra seria poupada se o desfecho do ataque fosse impedido a tempo. Além disso, a utilização de um avião como arma é assaz preocupante em face das características geográficas da República Federal da Alemanha, que ocupa um território relativamente pequeno e, ao mesmo tempo, densamente povoado. ${ }^{17}$

Cumpre registrar que uma das coligações do parlamento apresentou um requerimento em separado, esclarecendo que havia votado a favor da Lei de Segurança Aérea sob o pressuposto de que apenas o terrorista estivesse a bordo do avião. Tratando-se de um ataque a um avião de passageiros tripulado por pessoas inocentes, essa coligação manifestou seu entendimento no sentido de ser inconstitucional o dispositivo da Lei que autoriza o abate. ${ }^{18}$

Por sua vez, o governo federal defendeu a constitucionalidade do dispositivo em questão. Ele sustentou para tanto que a Lei de Segurança Aérea tem por objetivo garantir a proteção estatal a toda vida humana; quando o direito à vida de um cidadão colide com o direito à vida de outro cidadão, é dever do Estado, através da legislação, estabelecer uma solução para esse conflito. Não se trata de uma ponderação de vida contra vida, mas do reconhecimento de que a defesa em face de uma agressão à vida de determinados cidadãos deve ocorrer mesmo que, para isso, outros venham a perecer. A função de defesa, nesse caso, complementa a função de proteção, ambas funções de responsabilidade do Estado no que tange ao direito à vida. Especificamente em relação aos passageiros, eles acabam sendo, contra a sua vontade, parte da arma utilizada no ataque terrorista (no caso, a aeronave). Diante das ameaças que rodeiam o tráfego aéreo atualmente, o passageiro deve estar ciente do perigo a que se expõe quando decide embarcar em um avião; em outras palavras, deve saber que, em uma situação excepcional, pode ter a sua vida sacrificada para que se evite a

\footnotetext{
${ }^{15}$ Eis o texto do dispositivo mencionado: "Artigo 87a (2) Além da defesa, podem as forças armadas ser mobilizadas somente quando o autorizar expressamente essa Lei Fundamental.” No original: „Artikel 87a (2) Auber zur Verteidigung dürfen die Streitkräfte nur eingesetzt werden, soweit dieses Grundgesetz es ausdrücklich zuläbt."

${ }^{16}$ BVerfGE 115, 118.

${ }^{17}$ BVerfGE 115, 118.

${ }^{18}$ BVerfGE 115, 118.
} 
morte de outras pessoas. Além disso, a lei estabelece uma série de medidas que devem ser tomadas antes do emprego de violência contra o avião tripulado, o que está de acordo com o princípio da proporcionalidade e, mais além, com a consideração da dignidade humana dos passageiros. A autorização para o abate só pode ser dada quando se tem certeza de que a aeronave em questão está sendo parte de um ataque terrorista. ${ }^{19}$

\subsubsection{Fundamentação propriamente dita}

O Tribunal Constitucional Federal considerou o recurso constitucional admissível, na medida em que o recorrente encontra-se afetado atual e imediatamente em seus direitos fundamentais pela norma que pretende ver declarada inconstitucional, e, no mérito, considerou o $\S 14$, alínea 3 da Lei de Segurança Aérea incompatível com os direitos fundamentais à vida e à dignidade humana e, portanto, inconstitucional. Com isso, o recurso constitucional foi conhecido e provido. ${ }^{20}$ Os principais fundamentos da decisão serão expostos a seguir.

O direito à vida, garantido pelo artigo 2, alínea 2, frase 1 da Lei Fundamental é um direito de liberdade que garante que a existência biológica de todo ser humano não será agredida pelo Estado. Toda vida humana, sem exceção, está abrangida por esse direito fundamental. Apesar disso, o artigo 2, alínea 2, frase 3 da Lei Fundamental estabelece uma reserva de lei para esse direito. Isso significa que ele pode ser, sob determinadas circunstâncias, restringido por meio da legislação ordinária. Semelhante restrição, contudo, tem de observar, entre outras coisas, os limites que o próprio sistema constitucional estabelece para a garantia dos direitos fundamentais. ${ }^{21}$

No que tange especificamente à autorização para o abate de aviões, essa autorização e o consequente emprego de força contra a aeronave suspeita significam, com um grau de probabilidade muito próximo à certeza, a queda desse avião e a morte de todas as pessoas que se encontram a bordo, tanto dos terroristas quanto dos passageiros e do estafe da aeronave. Para tamanha brutalidade não se encontra nenhuma justificação do ponto de vista constitucional. ${ }^{22}$

Formalmente, ela é inconstitucional porque esse tipo de regulamentação foge à competência legislativa da Federação. Fora das hipóteses de defesa do território, as forças armadas alemãs só podem ser mobilizadas nos casos expressamente previstos na Lei Fundamental. Essa previsão da Lei de Segurança Aérea está (alegadamente) baseada no artigo 35, alínea 2 da Lei Fundamental, que autoriza a mobilização das forças armadas para auxiliar as forças policiais dos estados no caso de ocorrência de uma catástrofe natural ou de um desastre particularmente grave. ${ }^{23}$ Tal dispositivo, contudo, não autoriza o emprego de

\footnotetext{
${ }^{19}$ BVerfGE 115, 118.

${ }^{20}$ BVerfGE 115, 118.

${ }^{21}$ BVerfGE 115, 118.

22 BVerfGE 115, 118.

${ }^{23}$ Eis o texto do dispositivo mencionado: “Artigo 35 (2) Para a manutenção ou o restabelecimento da ordem pública podem os estados, em casos de especial significado, solicitar a força e as instalações da proteção federal às fronteiras para o suporte à sua polícia, quando a polícia não puder cumprir uma tarefa sem esse suporte, ou só puder fazê-lo com consideráveis dificuldades. Para o auxílio diante de uma catástrofe natural ou de um
} 
violência. A ajuda das forças armadas aos estados não inclui a possibilidade de uma ação bélica contra o causador da perturbação, como seria, por exemplo, o abate de um avião sequestrado por terroristas. ${ }^{24}$

Além disso, do ponto de vista material, o dispositivo correspondente ao $\S 14$, alínea 3 da Lei de Segurança Aérea é inconstitucional, na medida em que prevê a possibilidade de abate de uma aeronave tripulada por pessoas que não são criminosas, mas vítimas de um ataque à segurança aérea. Prevendo isso, o dispositivo em questão acaba por ferir o artigo 1 , alínea 1 da Lei Fundamental, que trata da inviolabilidade da dignidade humana, e o artigo 2, alínea 2, frase 1 da Lei Fundamental, que reconhece o direito à vida. Apenas se a previsão do abate fosse limitada a aviões não tripulados ou tripulados apenas por terroristas ela poderia ser entendida como constitucional. Não é esse, todavia, o caso, pois o dispositivo em questão permite a agressão a pessoas inocentes. ${ }^{25}$

O direito à vida está em íntima conexão com a dignidade humana, na medida em que a vida representa a base existencial da dignidade do ser humano, dignidade essa que, na Lei Fundamental, foi elevada ao ápice do sistema jurídico. Todo ser humano possui dignidade, e isso durante todo o período correspondente à sua existência física, independentemente de qualquer circunstância concreta. Para o Estado, a conexão entre o direito à vida e a dignidade humana tem duplo significado: a ele está proibido destruir, por medidas próprias, a vida humana e, ao mesmo tempo, tem ele o dever de proteger a vida humana contra perigos causados por terceiros. Nesse sentido, o artigo 1, alínea 1 da Lei Fundamental diz que é dever do Estado tanto respeitar a dignidade humana quanto protegê-la. ${ }^{26}$

Trata-se de uma norma constitucional de elevado grau de abstração. Concretamente, não se deixa reconhecer uma fórmula que determine em todos os casos o que significa a obrigação estatal de respeito e proteção à dignidade humana. Esse dever abrange a proteção do particular contra todos os tipos de ações do próprio Estado ou de terceiros que sejam nitidamente incompatíveis com a sua dignidade, especialmente contra aquelas que transformem o ser humano em um simples objeto do Estado. ${ }^{27}$

$\mathrm{O}$ argumento central para a inconstitucionalidade do dispositivo que permite $\mathrm{o}$ abate de aeronaves é o de que em uma situação na qual determinado avião foi tomado por terroristas e está sendo intencionalmente usado como arma contra a vida de pessoas inocentes (tanto das que estão a bordo quando das que se encontram no alvo que os terroristas pretendem atingir em terra), os passageiros são duplamente tratados como objeto, primeiro pelos terroristas e depois pelo Estado. No caso, o objetivo da ação estatal é evitar que $o$ ataque terrorista chegue a termo, de modo a salvar aqueles que seriam as suas

\footnotetext{
desastre especialmente grave pode um estado solicitar forças policiais de outros estados, força e instalações de outras administrações, bem como da proteção federal às fronteiras e das forças armadas." No original: „Artikel 35 (2) Zur Aufrechterhaltung oder Wiederherstellung der öffentlichen Sicherheit oder Ordnung kann ein Land in Fällen von besonderer Bedeutung Kräfte und Einrichtungen des Bundesgrenzschutzes zur Unterstützung seiner Polizei anfordern, wenn die Polizei ohne diese Unterstützung eine Aufgabe nicht oder nur unter erheblichen Schwierigkeiten erfüllen könnte. Zur Hilfe bei einer Naturkatastrophe oder bei einem besonders schweren Unglücksfall kann ein Land Polizeikräfte anderer Länder, Kräfte und Einrichtungen anderer Verwaltungen sowie des Bundesgrenzschutzes und der Streitkräfte anfordern."

${ }^{24}$ BVerfGE 115, 118.

25 BVerfGE 115, 118.

${ }^{26}$ BVerfGE 115, 118.

${ }^{27}$ BVerfGE 115, 118.
} 
potenciais vítimas em terra; todavia, isso não elimina a violação à dignidade das pessoas que estão dentro do avião e que são conscientemente agredidas pelo Estado, uma agressão que, para elas, muito provavelmente terá como consequência a morte. A eliminação das vítimas a bordo acaba sendo o meio para a salvação das potenciais vítimas no solo, ou seja, as pessoas a bordo são tratadas como coisas, o que não é compatível com o seu direito à vida e com a proteção da sua dignidade. ${ }^{28}$

A favor da inconstitucionalidade do dispositivo em questão pode ser levantado um argumento adicional: o da incerteza. Quando esse tipo de incidente ocorre, as circunstâncias que autorizam o emprego de violência contra o avião suspeito nem sempre podem ser cuidadosamente avaliadas. A própria determinação da existência de um fato potencialmente provocador de um desastre, nos termos da Lei de Segurança Aérea, é, não raro, rodeada de grandes incertezas. A questão, aqui, é até que ponto o estafe de bordo tem a capacidade de informar corretamente o pessoal em terra acerca da existência de um ataque. Se o sequestro do avião for tão bem executado que não seja possível informar adequadamente os órgãos de segurança aérea acerca do que está ocorrendo, a real situação permanece incerta desde o início para aqueles que devem tomar providências em terra. Além disso, como essa é uma situação de combate, não pode ser descartada a priori a possibilidade de uma reação do estafe da aeronave e dos passageiros, o que significa que a situação a bordo pode se alterar completamente em questão de minutos, e uma eventual retomada do controle do avião pode não ser informada a tempo às autoridades que devem tomar a decisão acerca do abate. ${ }^{29}$

Some-se a isso que a própria motivação do sequestrador do avião permanece totalmente obscura até que ele próprio se manifeste ou que o seu objetivo esteja prestes a ser atingido. Diante de toda essa incerteza, a autorização para abrir fogo contra a aeronave pode se revelar totalmente desproporcional, ou seja, corre-se o altíssimo risco de reagir com demasia, potencializado pela gigantesca pressão de tempo que pesa sobre a decisão. ${ }^{30}$

\subsection{A BVERFGE 115, 118 À LUZ DA TEORIA DA PONDERAÇÃO}

A decisão exposta no item anterior provocou uma série de reações no âmbito da literatura jurídica alemã. Manifestações especialmente frutíferas acerca dela, capazes de explicá-la analiticamente com alto grau de precisão, foram trazidas pelos autores da assim chamada "Escola de Kiel". O pensamento desses autores está na base das reflexões seguintes.

\subsubsection{A distinção entre regras e princípios}

De acordo com o grande representante da Escola de Kiel, Robert Alexy, existem duas espécies de normas: regras e princípios. Regras contêm fixações no âmbito do possível fática e juridicamente; isso significa que, se uma regra vale e é aplicável, deve-se fazer exatamente aquilo que ela pede. Uma regra somente pode ser cumprida ou não cumprida, ou seja, seu cumprimento é uma questão de tudo ou nada. Normas com caráter de regra são

\footnotetext{
28 BVerfGE 115, 118.

${ }^{29}$ BVerfGE 115, 118.

${ }^{30}$ BVerfGE 115, 118.
} 
"mandamentos definitivos". Princípios, por sua vez, exigem que algo seja cumprido em uma medida máxima possível em atenção às possibilidades fáticas e jurídicas existentes. Constituem, portanto, "mandamentos de otimização", que admitem cumprimento em diferentes graus, em atenção às circunstâncias fáticas e jurídicas do caso (essas últimas representadas pelas regras e - mormente - pelos princípios em sentido contrário). ${ }^{31}$

Essa distinção possui numerosas consequências, e as discussões teóricas em torno dela parecem longe de terminar. ${ }^{32}$ Aqui, o mais importante a ressaltar é que a distinção qualitativa entre regras e princípios, na forma proposta por Alexy, leva a duas distintas formas de aplicação do direito: regras são aplicáveis mediante subsunção, enquanto princípios o são mediante ponderação. Normas de direitos fundamentais são, via de regra, normas de caráter principiológico. ${ }^{33}$ Isso significa que elas não determinam de antemão o seu conteúdo concreto de dever-ser: essa determinação somente pode ser buscada no caminho da solução do conflito entre os princípios colidentes no caso concreto.

\subsubsection{Princípios, proporcionalidade e ponderação}

Mais além, a estrutura dos princípios deve ser entendida a partir da conexão desse tipo de norma com o princípio da proporcionalidade. Tanto a proporcionalidade como tal quanto os seus três princípios parciais (idoneidade, necessidade e proporcionalidade em sentido restrito) decorrem logicamente da ideia de princípio. ${ }^{34}$

Como mandamentos de otimização, princípios ordenam a realização de algo em uma medida máxima possível relativamente às possibilidades jurídicas e fáticas. Os princípios da idoneidade e da necessidade representam a natureza dos princípios como mandamentos de otimização relativamente às possibilidades fáticas; o princípio da proporcionalidade em sentido restrito, que consiste justamente na exigência de ponderação, representa a natureza dos princípios como mandamentos de otimização relativamente às possibilidades jurídicas. ${ }^{35}$

\subsubsection{Duas leis da ponderação}

A ponderação é o objeto do exame da proporcionalidade em sentido restrito. Com ela, determina-se o que é a otimização relativamente às possibilidades jurídicas. Nesse sentido, o terceiro subprincípio da proporcionalidade pode ser expresso na forma de uma "lei

\footnotetext{
${ }^{31}$ ALEXY, Robert. Theorie der Grundrechte. 2. Aufl. Frankfurt am Main: Suhrkamp, 1994. S. 75-77.

${ }^{32}$ Para uma análise das críticas à distinção proposta por Alexy no âmbito da doutrina brasileira, ver TREVISAN, Leonardo Simchen. Ponderação, Argumentação, Racionalidade: Robert Alexy e Seus Críticos. Porto Alegre: Sergio Antonio Fabris, 2017. p. 173-292.

${ }^{33}$ Há exceções, como a norma de direito fundamental associada, que têm a estrutura correspondente às regras e deve, portanto, ser aplicada mediante subsunção. Sobre esse conceito, ver ALEXY, Robert. Theorie der Grundrechte. 2. Aufl. Frankfurt am Main: Suhrkamp, 1994. S. 57-63; LUDWIG, Roberto José. A Norma de Direito Fundamental Associada: Direito, Moral, Política e Razão em Robert Alexy. Porto Alegre: Sergio Antonio Fabris, 2014. p. 31-56.

${ }^{34}$ ALEXY, Robert. Theorie der Grundrechte. 2. Aufl. Frankfurt am Main: Suhrkamp, 1994. S. 100.

${ }^{35}$ ALEXY, Robert. Theorie der Grundrechte. 2. Aufl. Frankfurt am Main: Suhrkamp, 1994. S. 100-101.
} 
da ponderação", que diz: "quanto mais alto é o grau do não cumprimento ou prejuízo de um princípio, tanto maior deve ser a importância do cumprimento do outro."36

Essa primeira lei da ponderação constitui o grande axioma a aplicar na colisão de princípios. A ponderação, todavia, não se resume à determinação das intensidades de intervenção e da importância relativa dos princípios em colisão. Ela envolve também os pesos abstratos de cada um desses princípios no caso concreto e os graus de segurança empírica acerca das medidas de intervenção em cada princípio. Com relação a esse último fator, é possível formular uma segunda lei da ponderação, que leva o nome de lei da ponderação epistêmica. Ela diz: "quanto mais grave pesa uma intervenção em um direito fundamental, tanto maior deve ser a certeza das premissas apoiadoras dessa intervenção." ${ }^{37}$ Para o tema aqui discutido, essa segunda lei da ponderação é, como adiante se verá, fundamental.

\subsubsection{A fórmula peso}

Todas essas variáveis aparentemente díspares deixam-se reunir em um modelo matemático extremamente relevante para a teoria da ponderação: a fórmula peso.

De acordo com essa construção teórica, o peso concreto $\left(G_{i, j}\right)$ de um princípio $\left(P_{i}\right)$ em face de um princípio em sentido contrário $\left(P_{j}\right)$ pode ser expresso numericamente pelo quociente da divisão do produto da multiplicação dos valores correspondentes à intensidade de intervenção em $P_{i}\left(l_{i}\right)$, ao peso abstrato de $P_{i}\left(G_{i}\right)$ e ao grau de segurança da suposição empírica acerca da não realização de $P_{i}\left(S_{i}\right)$ pelo produto da multiplicação dos valores correspondentes à intensidade de intervenção em $P_{j}\left(l_{j}\right)$, ao peso abstrato de $P_{j}\left(G_{j}\right)$ e ao grau de segurança da suposição empírica acerca da não realização de $P_{j}\left(S_{j}\right){ }^{38}$ Sendo essas as variáveis, a fórmula pode ser expressa da seguinte forma:

$$
G_{i, j}=\left(I_{i} \times G_{i} \times S_{i}\right) \div\left(I_{j} \times G_{j} \times S_{j}\right)^{39}
$$

Naturalmente, nada foi dito ainda acerca da possibilidade de atribuições numéricas a dessas variáveis, tampouco acerca da correra interpretação do resultado. $G_{i, j}$ expressa, como visto, o peso concreto do princípio $P_{i}$ em relação ao princípio $P_{j}$, ambos em rota de colisão. Se, aplicada a fórmula peso, o valor de $G_{i, j}$ for superior a $1, P_{i}$ prevalece sobre $P_{j}$; se for inferior a $1, P_{j}$ prevalece sobre $P_{i}$; se for igual a 1 , há um empate, o que significa que nenhum princípio

\footnotetext{
${ }^{36}$ ALEXY, Robert. Direitos Fundamentais, Ponderação e Racionalidade. in: Idem. Constitucionalismo Discursivo. Tradução de Luís Afonso Heck. 4. ed. Porto Alegre: Livraria do Advogado, 2015. p. 111.

${ }^{37}$ ALEXY, Robert. A Fórmula Peso. in: Idem. Constitucionalismo Discursivo. Tradução de Luís Afonso Heck. 4. ed. Porto Alegre: Livraria do Advogado, 2015. p. 150.

${ }^{38}$ ALEXY, Robert. A Fórmula Peso. in: Idem. Constitucionalismo Discursivo. Tradução de Luís Afonso Heck. 4. ed. Porto Alegre: Livraria do Advogado, 2015. p. 138-150.

${ }^{39}$ ALEXY, Robert. A Fórmula Peso. in: Idem. Constitucionalismo Discursivo. Tradução de Luís Afonso Heck. 4. ed. Porto Alegre: Livraria do Advogado, 2015. p. 151.
} 
prevalece (e, portanto, a ponderação não é capaz de oferecer uma solução para o caso - tratase da possibilidade de um "espaço de ponderação", que não será abordada aqui). ${ }^{40}$

Além disso, as atribuições numéricas às variáveis da fórmula dependem, naturalmente, de diferenciações. Com relação à primeira variável $l_{i}$, que significa a intensidade de intervenção no princípio $P_{i}$ diante do caso concreto, pode-se reconhecer, no quadro de uma escalação triádica, três graus de intervenção: leve $(l)$, médio $(m)$ e grave $(s)$. Tomando-se por base uma escalação geométrica, é possível atribuir a I o número $1\left(2^{\circ}\right)$; a $m$, o número 2 $\left(2^{1}\right)$; e a $s$, o número $4\left(2^{2}\right)$. $l_{j}$ representa a intensidade de intervenção em $P_{j}$ por omissão da intervenção em $P_{i}$. De forma análoga ao que ocorre em $l_{i}$, a intervenção em $P_{j}$ será sempre concreta, sendo idênticos também os graus de intervenção $(I, m, s)$. $G$ representa o peso abstrato de $P_{i}$, ou seja, o peso que $P_{i}$ possui abstratamente em relação aos demais princípios, independentemente das circunstâncias do caso; $G_{j}$ representa algo idêntico em relação a $P_{j}$. A escala triádica pode ser aplicada também aos pesos abstratos; se eles forem iguais, o que frequentemente acontece, acabam por neutralizar-se reciprocamente. Por último, $S_{i}$ e $S_{j}$ representam o grau de segurança da suposição empírica acerca da intensidade da intervenção nos respectivos princípios no caso concreto. Também aqui é possível uma escalação triádica: certo ou seguro $(g)$, sustentável ou plausível $(p)$ e não evidentemente falso $(e)$, aos quais os seguintes valores numéricos podem ser atribuídos: $2^{0}$ (ou seja, 1 ) para $g, 2^{-1}$ (ou seja, 1/2) para $p$ e $2^{-2}$ (ou seja, $1 / 4$ ) para $e^{41}$

Isso posto, torna-se possível reconhecer que, na fórmula peso, estão expressas analiticamente tanto a primeira lei da ponderação, segundo a qual um grau ascendente de não cumprimento ou prejuízo de um princípio deve ser acompanhado de uma importância tanto maior do cumprimento do outro, representada pelas variáveis $l_{i}$ e $l_{j}$, quanto a segunda lei da ponderação, segundo a qual a gravidade crescente de uma intervenção em um direito fundamental deve ser justificada por uma certeza tanto maior das premissas apoiadoras da intervenção, representada pelas variáveis $S_{i}$ e $S_{j}$. Acrescentando-se as variáveis $G_{i}$ e $G_{j}$, correspondentes aos pesos abstratos, tem-se um modelo analítico extremamente rigoroso que, em seu conjunto, pode ser entendido como a "justificação interna" da ponderação. A imagem, contudo, ainda não está completa. De acordo com a fórmula peso, a ponderação depende de asserções quanto aos graus correspondentes a cada um dos fatores envolvidos. Isso somente pode ser feito no caminho da argumentação jurídica racional. ${ }^{42} \mathrm{O}$ modelo de ponderação de Alexy é, portanto, um modelo fundamentado. ${ }^{43}$ A fundamentação,

\footnotetext{
${ }^{40}$ Sobre isso, ver ALEXY, Robert. Direito Constitucional e Direito Ordinário - Jurisdição Constitucional e Jurisdição Especializada. in: Idem. Constitucionalismo Discursivo. Tradução de Luís Afonso Heck. 4. ed. Porto Alegre: Livraria do Advogado, 2015. p. 81-85.

${ }^{41}$ ALEXY, Robert. A Fórmula Peso. in: Idem. Constitucionalismo Discursivo. Tradução de Luís Afonso Heck. 4. ed. Porto Alegre: Livraria do Advogado, 2015. p. 138-151.

${ }^{42}$ Poder-se-ia levantar contra a fórmula peso a objeção de que ela promoveria uma "matematização do direito", estabelecendo a pretensão de atingir um grau de exatidão que ela não é capaz de cumprir. Isso seria, contudo, um equívoco. A adequada compreensão da fórmula peso mostra que o que existe é tão somente um modelo aritmético voltado a estruturar formalmente a ponderação. As atribuições numéricas às variáveis da fórmula carecem de justificação, ou seja, o campo da argumentação jurídica racional não é abandonado. Dizer que a fórmula peso reduz o direito à matemática faz tão pouco sentido quanto dizer que o silogismo de subsunção reduz o direito à lógica formal.

${ }^{43}$ No que se refere à racionalidade da ponderação, Alexy contrapõe dois modelos distintos. O "modelo de fundamentação", que o referido autor defende, caracteriza-se por promover o enlace entre o procedimento da ponderação e a teoria da argumentação jurídica racional. O modelo oposto, um "modelo de decisão",
} 
indissociavelmente unida à racionalidade, representa, com isso, a "justificação externa" da ponderação. ${ }^{44}$

Para os objetivos aqui perseguidos, essa singela exposição da estrutura da fórmula peso é suficiente. Na sequência, buscar-se-á demonstrar que, ao permitir que a intensidade de intervenção em um princípio seja posta em relação com o grau de insegurança empírica que se tem acerca da medida que ocasiona a intervenção, essa fórmula permite que a decisão do Tribunal Constitucional Federal acerca do abate de aviões seja explicada de modo analiticamente rigoroso.

\subsubsection{A insegurança empírica como fator determinante para o juízo de ponderação no caso do abate de aviões}

Mencionou-se anteriormente que um dos argumentos centrais para a inconstitucionalidade da norma que autoriza o abate de aviões diz respeito à insegurança empírica. ${ }^{45}$ Com efeito, a decisão estabelece claramente que os pressupostos para a autorização do abate da aeronave suspeita não podem ser demonstrados com a certeza necessária, especialmente no que se refere às reais intenções do terrorista, ou seja, se ele de

certamente não é capaz de garantir qualquer racionalidade, pois pressupõe que a ponderação seja efetuada exclusivamente com base nas inclinações subjetivas daquele que decide. Contra esse modelo pode ser feito valer que, em uma ponderação corretamente efetuada, não se trata de subjetividade e decisionismo. O modelo de fundamentação não está certamente em condições de fornecer um procedimento de ponderação que leve, em todos os casos, a um único resultado possível, mas é capaz de estruturar racionalmente a argumentação, ao determinar aquilo que, a cada vez, deve ser fundamentado. Da união entre ponderação e argumentação resulta a possibilidade de um controle intersubjetivo das decisões, ou seja, essa união é uma garantia de racionalidade. (ALEXY, Robert. Theorie der Grundrechte. 2. Aufl. Frankfurt am Main: Suhrkamp, 1994. S. 144-152.)

${ }^{44}$ A justificação interna e a justificação externa são os dois tipos de justificação verificados no discurso jurídico. A justificação interna diz respeito à dedutibilidade de uma decisão a partir das premissas utilizadas em sua fundamentação; a segunda trata da correção dessas premissas. (ALEXY, Robert. Theorie der Juristischen Argumentation: die Theorie des Rationalen Diskurses als Theorie der Juristischen Begründung. 2. Aufl. Frankfurt am Main: Suhrkamp, 1991. S. 273.) No específico âmbito da ponderação, a terminologia "justificação interna" e "justificação externa" (que Alexy concebera originalmente para a subsunção) foi empregada pela primeira vez por Klatt e Schmidt: "Relacionada com a ponderação a justificação interna concerne à questão, se o resultado da ponderação resulta, segundo as regras da aritmética, das premissas citadas para a fundamentação. A questão da justificação interna deixa responder-se por uma consideração da estrutura formal da ponderação, como ela está descrita na fórmula peso. Estão fixados os valores a serem colocados na fórmula peso para as variáveis particulares, então pode o resultado ser derivado segundo as regras da aritmética. Do mesmo modo como na justificação interna de sentenças segundo o silogismo judicial, que certamente não segue regras aritméticas, mas lógicas, trata-se nisso, exclusivamente, de uma estrutura formal. Nem o silogismo judicial nem a fórmula peso concernem à correção das premissas colocadas. Trata-se, nesse aspecto, em ambos os casos, somente da relação inferencial da derivação de um resultado de premissas dadas. A correção das premissas é, pelo contrário, objeto da justificação externa. Aqui se trata disto, de fundamentar os valores colocados na fórmula peso. Portanto, por exemplo, da justificação, que a intensidade da intervenção foi avaliada como 'grave' ou da justificação, que o peso do princípio em sentido contrário somente é leve." (KLATT, Matthias; SCHMIDT, Johannes. Espaços no Direito Público: Para a Doutrina da Ponderação da Teoria dos Princípios. Tradução de Luís Afonso Heck. Porto Alegre: Sergio Antonio Fabris, 2015. p. 37.)

${ }^{45}$ Ver item 1.1.2, supra. 
fato pretende provocar a queda do avião, e também se, mesmo que ele tenha essa intenção, outras vítimas podem ser feitas além daquelas que se encontram a bordo da aeronave. ${ }^{46}$

Assim, verifica-se uma ponderação entre o dever do Estado relativamente à proteção do cidadão contra ataques terroristas e o direito à vida, em conexão com a dignidade humana, das pessoas que estão a bordo da aeronave suspeita. Nessa ponderação, a intensidade de intervenção no direito à vida dos passageiros é evidentemente grave, na medida em que o abate do avião representa a morte quase certa para aqueles que estão a bordo. De outro lado, há o dever estatal de proteção à vida das pessoas que, em terra, se acham ameaçadas pelo ataque terrorista em curso; a importância de satisfação dessa exigência é igualmente alta. Com isso, verifica-se uma intervenção grave em um princípio justificada por um fundamento de intervenção que pesa gravemente. ${ }^{47}$

Disso decorre que, se apenas a primeira lei da ponderação fosse utilizada, a autorização para o abate de aviões poderia, em tese, ser admissível. Ela, contudo, não o é, em face da segunda lei da ponderação. Considerando a pressão de tempo que pesa sobre a autoridade encarregada de tomar a decisão, é praticamente impossível avaliar com cuidado se os pressupostos previstos em lei para o abate da aeronave estão presentes. A decisão é tomada por mera suspeita, não por um conhecimento seguro acerca do conjunto da situação. Isso não se coaduna com a lei de ponderação epistêmica, que exige que a segurança empírica tenha de ser tanto mais alta quanto mais pesada for a intervenção. Uma intervenção grave no direito à vida dos passageiros somente poderia ser justificada se houvesse um fundamento de intervenção relativamente seguro; no caso, se fosse possível a obtenção de certeza acerca da existência de um ataque terrorista e da motivação do criminoso no sentido de vitimar outras pessoas em terra com a derrubada do avião. Todavia, uma certeza quanto a esses fatores é difícil (talvez até mesmo impossível) de obter. A insegurança empírica é, portanto, o fator decisivo para que a medida correspondente ao abate da aeronave seja considerada inconstitucional no âmbito do juízo de ponderação. ${ }^{48}$

A estrutura da fórmula peso facilita a compreensão da decisão. ${ }^{49}$ Utilizando-se as escalas descritas anteriormente, tanto as intensidades de intervenção no direito à vida dos passageiros pelo abate da aeronave $\left(l_{i}\right)$ quanto a importância da proteção à vida das pessoas no solo $\left(l_{j}\right)$ podem ser expressas numericamente como $2^{2}$ (intervenção grave/importância alta). Como se trata, em ambos os lados, do direito à vida, os pesos abstratos dos princípios devem ser tidos como iguais e, portanto, podem ser desprezados. No que tange às suposições relativas aos graus de segurança empírica, a variável $S_{j}$ deve ser expressa por $2^{0}$, já que existe segurança sobre o grau de afetação do direito à vida dos passageiros em caso de abate. $A$ variável $S_{i}$, por sua vez, deve ser expressa por $2^{-1}$, já que a segurança acerca da existência de um perigo real é, no máximo, mediana. Assim, tem-se que $G_{i, j}=\left(2^{2} \times 2^{0}\right) \div\left(2^{2} \times 2^{-1}\right)=2$, ou

\footnotetext{
${ }^{46}$ KLATT, Matthias; SCHMIDT, Johannes. Espaços no Direito Público: Para a Doutrina da Ponderação da Teoria dos Princípios. Tradução de Luís Afonso Heck. Porto Alegre: Sergio Antonio Fabris, 2015. p. 39-40.

47 KLATT, Matthias; SCHMIDT, Johannes. Espaços no Direito Público: Para a Doutrina da Ponderação da Teoria dos Princípios. Tradução de Luís Afonso Heck. Porto Alegre: Sergio Antonio Fabris, 2015. p. 44.

${ }^{48}$ KLATT, Matthias; SCHMIDT, Johannes. Espaços no Direito Público: Para a Doutrina da Ponderação da Teoria dos Princípios. Tradução de Luís Afonso Heck. Porto Alegre: Sergio Antonio Fabris, 2015. p. 62-64.

${ }^{49}$ Ver item 1.2.2.2, supra.
} 
seja, $P_{i}$ prepondera sobre $P_{j}$, de modo a excluir juridicamente a possibilidade de derrubamento da aeronave. ${ }^{50}$

Com isso, obtém-se um quadro completo da justificação interna da decisão. A justificação externa pode ser buscada na sua fundamentação, especialmente no que tange às asserções acerca dos graus de insegurança empírica, que, como visto, desempenham, no presente caso, um papel decisivo. ${ }^{51}$ Resta demonstrado, assim, não apenas o potencial analítico da fórmula peso, mas também sua utilidade e relevância para o correto entendimento das decisões de ponderação.

\section{O ABATE DE AVIÕES NO BRASIL}

\subsection{LEGISLAÇÃO BRASILEIRA SOBRE ABATE DE AVIÕES}

O uso do espaço aéreo brasileiro é regulado pelo Código Brasileiro de Aeronáutica (Lei n.o 7.565/86), ${ }^{52}$ que, originalmente, não previa qualquer autorização para o abate de aeronaves civis. Alguns anos depois da promulgação do CBA, contudo, o seu artigo 303 foi alterado pela Lei n.o 9.614/98, passando a admitir essa possibilidade. Hoje, o dispositivo em questão do CBA está assim redigido:

Art. 303. A aeronave poderá ser detida por autoridades aeronáuticas, fazendárias ou da Polícia Federal, nos seguintes casos:

I - se voar no espaço aéreo brasileiro com infração das convenções ou atos internacionais, ou das autorizações para tal fim;

II - se, entrando no espaço aéreo brasileiro, desrespeitar a obrigatoriedade de pouso em aeroporto internacional;

III - para exame dos certificados e outros documentos indispensáveis;

IV - para verificação de sua carga no caso de restrição legal (artigo 21) ou de porte proibido de equipamento (parágrafo único do artigo 21);

V - para averiguação de ilícito.

$\S 1^{\circ} \mathrm{A}$ autoridade aeronáutica poderá empregar os meios que julgar necessários para compelir a aeronave a efetuar o pouso no aeródromo que lhe for indicado.

$\S 2^{\circ}$ Esgotados os meios coercitivos legalmente previstos, a aeronave será classificada como hostil, ficando sujeita à medida de destruição, nos casos dos incisos do caput deste artigo e após autorização do Presidente da República ou autoridade por ele delegada.

$\S 3^{\circ} \mathrm{A}$ autoridade mencionada no $\S 1^{\circ}$ responderá por seus atos quando agir com excesso de poder ou com espírito emulatório. ${ }^{53}$

\footnotetext{
${ }^{50}$ KLATT, Matthias; SCHMIDT, Johannes. Espaços no Direito Público: Para a Doutrina da Ponderação da Teoria dos Princípios. Tradução de Luís Afonso Heck. Porto Alegre: Sergio Antonio Fabris, 2015. p. 64-65.

${ }^{51}$ Ver item 1.1.2, supra.

52 Doravante será utilizada tão somente a sigla CBA.

${ }^{53}$ A alteração promovida pela Lei n. 9 9.614/98 consistiu precisamente na introdução do § 2ㅇ ao artigo 303 da Lei n. ㅇ 7.565/86, renumerando-se o seu antigo § 2 은 como § 3 .
} 
Saliente-se, ainda, que os $\S \S 10$, 2 e 3 do dispositivo supratranscrito foram objeto de regulamentação pelo Decreto Presidencial n.o 5.144/04. O decreto em questão dispõe o seguinte:

Art. 1을 Este Decreto estabelece os procedimentos a serem seguidos com relação a aeronaves hostis ou suspeitas de tráfico de substâncias entorpecentes e drogas afins, levando em conta que estas podem apresentar ameaça à segurança pública.

Art. 2ำ Para fins deste Decreto, é considerada aeronave suspeita de tráfico de substâncias entorpecentes e drogas afins aquela que se enquadre em uma das seguintes situações:

I - adentrar o território nacional, sem Plano de Vôo aprovado, oriunda de regiões reconhecidamente fontes de produção ou distribuição de drogas ilícitas; ou

II - omitir aos órgãos de controle de tráfego aéreo informações necessárias à sua identificação, ou não cumprir determinações destes mesmos órgãos, se estiver cumprindo rota presumivelmente utilizada para distribuição de drogas ilícitas.

Art. 3을 As aeronaves enquadradas no art. 2을 estarão sujeitas às medidas coercitivas de averiguação, intervenção e persuasão, de forma progressiva e sempre que a medida anterior não obtiver êxito, executadas por aeronaves de interceptação, com o objetivo de compelir a aeronave suspeita a efetuar o pouso em aeródromo que lhe for indicado e ser submetida a medidas de controle no solo pelas autoridades policiais federais ou estaduais.

$\S 1$ 을 As medidas de averiguação visam a determinar ou a confirmar a identidade de uma aeronave, ou, ainda, a vigiar o seu comportamento, consistindo na aproximação ostensiva da aeronave de interceptação à aeronave interceptada, com a finalidade de interrogá-la, por intermédio de comunicação via rádio ou sinais visuais, de acordo com as regras de tráfego aéreo, de conhecimento obrigatório dos aeronavegantes.

$\S 20$ As medidas de intervenção seguem-se às medidas de averiguação e consistem na determinação à aeronave interceptada para que modifique sua rota com o objetivo de forçar o seu pouso em aeródromo que lhe for determinado, para ser submetida a medidas de controle no solo.

§ 3으 As medidas de persuasão seguem-se às medidas de intervenção e consistem no disparo de tiros de aviso, com munição traçante, pela aeronave interceptadora, de maneira que possam ser observados pela tripulação da aeronave interceptada, com o objetivo de persuadi-la a obedecer às ordens transmitidas.

Art. 4으 A aeronave suspeita de tráfico de substâncias entorpecentes e drogas afins que não atenda aos procedimentos coercitivos descritos no art. 3o será classificada como aeronave hostil e estará sujeita à medida de destruição.

Art. 5 A medida de destruição consiste no disparo de tiros, feitos pela aeronave de interceptação, com a finalidade de provocar danos e impedir o prosseguimento do vôo da aeronave hostil e somente poderá ser utilizada como último recurso e após o cumprimento de todos os procedimentos que previnam a perda de vidas inocentes, no ar ou em terra.

Art.6ำ A medida de destruição terá que obedecer às seguintes condições:

I - emprego dos meios sob controle operacional do Comando de Operações Aeroespaciais do Comando da Aeronáutica;

II - registro em gravação das comunicações ou imagens da aplicação dos procedimentos; 
III - execução por pilotos e controladores de defesa aérea qualificados segundo os padrões estabelecidos pelo Comando de Operações Aeroespaciais do Comando da Aeronáutica;

IV - execução sobre áreas não densamente povoadas e relacionadas com rotas presumivelmente utilizadas para o tráfico de substâncias entorpecentes e drogas afins; e

V - autorização do Presidente da República ou da autoridade por ele delegada.

Art. 7ㅇ O teor deste Decreto deverá ser divulgado, antes de sua vigência, por meio da Publicação de Informação Aeronáutica (AIP Brasil), destinada aos aeronavegantes e de conhecimento obrigatório para o exercício da atividade aérea no espaço aéreo brasileiro.

Art. 8ㅇ As autoridades responsáveis pelos procedimentos relativos à execução da medida de destruição responderão, cada qual nos limites de suas atribuições, pelos seus atos, quando agirem com excesso ou abuso de poder.

Art. 9o Os procedimentos previstos neste Decreto deverão ser objeto de avaliação periódica, com vistas ao seu aprimoramento.

Art. 10. Fica delegada ao Comandante da Aeronáutica a competência para autorizar a aplicação da medida de destruição.

Art. 11. O Ministério da Defesa, por intermédio do Comando da Aeronáutica, deverá adequar toda documentação interna ao disposto neste Decreto.

Art. 12. Este Decreto entra em vigor noventa dias após a data de sua publicação. ${ }^{54}$

Em uma análise comparativa, é possível reconhecer uma miríade de pontos em comum entre a legislação brasileira e a alemã. Assim, o § 1 o do artigo 303 do CBA estabelece que as autoridades aéreas podem utilizar dos meios que estão à sua disposição para forçar a aeronave classificada como hostil a aterrissar (classificadas pelo Decreto n.o 5.144/04 em medidas de averiguação, intervenção e persuasão, com grau crescente de intensidade); nos termos do $\S 2$ o do artigo 303 do CBA, a medida de destruição da aeronave só pode ser empregada quando esgotados os meios menos gravosos de sua interceptação. O paralelismo com a legislação alemã não poderia ser mais nítido, especialmente com o § 14, alínea 3 da Lei de Segurança Aérea, que estabelece a possibilidade de uma agressão à aeronave hostil apenas quando as medidas mais brandas de interceptação (semelhantes às previstas nos $\S \S 10,20 \mathrm{e}$ 3어 do artigo 3ㅇ do Decreto n. - 5.144/04) revelarem-se infrutíferas. Quanto ao propósito, todavia, verifica-se uma diferença extremamente significativa: a legislação alemã trata de casos de terrorismo, enquanto a brasileira é voltada a coibir o tráfico internacional de entorpecentes. ${ }^{55}$

\footnotetext{
${ }^{54}$ Essa é a redação atual. Cumpre registrar, a propósito, que os incisos I e III do artigo 6o do referido Decreto possuíam originalmente uma outra redação, que foi alterada pelo Decreto n.o 9.077/17.

${ }^{55}$ Sobre o teor da legislação alemã, ver item 1.1.1, supra.
} 


\section{2 É CONSTITUCIONAL A PERMISSÃO PARA O ABATE DE AVIÕES NO ESPAÇO AÉREO BRASILEIRO?}

Sendo esse o teor da legislação brasileira, coloca-se a questão de sua conformidade com a Constituição da República Federativa do Brasil. ${ }^{56} \mathrm{~A}$ seguir, serão tecidas breves considerações a esse respeito, procurando-se traçar paralelos com a experiência alemã.

Trata-se de uma típica questão de ponderação. ${ }^{57} \mathrm{Na}$ admissão do abate de aeronaves hostis, deixa-se vislumbrar uma colisão entre os princípios que garantem, de um lado, o direito à vida dos tripulantes, e, de outro, a segurança pública (entendida, nesse contexto, como a necessidade de repressão ao tráfico de entorpecentes).

O direito à vida é um dos direitos consagrados no caput do artigo 5o da CRFB, o texto magno que também consagra, em seu artigo 1으, inciso III, a dignidade da pessoa humana. Não poderia ser diferente: como salienta José Afonso da Silva, de nada adiantaria a Constituição prever outros direitos fundamentais se não erigisse a vida humana no mais básico desses direitos, ao qual a própria noção de dignidade humana pode ser reconduzida. ${ }^{58}$ Ao mesmo tempo, a garantia da segurança pública encontra-se prevista no artigo 144 da CRFB, que a descreve como dever do Estado e direito e responsabilidade de todos, tendo por finalidade a preservação da ordem pública e da incolumidade das pessoas e do patrimônio. ${ }^{59}$

Tomando-se em conta a primeira lei da ponderação, segundo a qual o grau de prejuízo à realização de um princípio só pode ser justificado por um grau correspondente de importância do cumprimento do princípio em sentido contrário, verifica-se, de um lado, o direito à vida dos tripulantes da aeronave suspeita sendo afetado de maneira grave, pois a aplicação da medida de destruição muito provavelmente acarretará a morte deles. ${ }^{60}$

O princípio em sentido contrário, qual seja, o da garantia segurança pública, seria afetado apenas de forma leve (no máximo mediana) se a destruição da aeronave fosse proibida. $O$ tráfico de drogas representa um grave problema no Brasil, sem dúvida, não apenas

\footnotetext{
${ }^{56}$ Doravante será utilizada tão somente a sigla CRFB.

57 Sobre a teoria da ponderação, ver item 1.2.2, supra.

${ }^{58}$ SILVA, José Afonso da. Curso de Direito Constitucional Positivo. 32. ed. São Paulo: Malheiros, 2009. p. 198.

59 Um tema particularmente espinhoso é o da atuação das Forças Armadas (Exército, Marinha e Aeronáutica) na segurança pública. De fato, o artigo 144 da CRFB enumera em seus incisos (no total de cinco) os órgãos responsáveis por essa função, quais sejam, a polícia federal, a polícia rodoviária federal, a polícia ferroviária federal, as polícias civis, as polícias militares e os corpos de bombeiros militares. As Forças Armadas não estão incluídas nesse rol: suas funções, nos termos do artigo 142 da CRFB, limitam-se à defesa nacional, à garantia dos poderes constitucionais e, por iniciativa de qualquer dos poderes, à manutenção da lei e da ordem. No que tange a essa última função das Forças Armadas, deve ser observado que "só subsidiária e eventualmente lhes incumbe a defesa da lei e da ordem, porque essa defesa é de competência primária das forças de segurança pública". (SILVA, José Afonso da. Curso de Direito Constitucional Positivo. 32. ed. São Paulo: Malheiros, 2009. p. 772.) 0 § 1 ㅇdo artigo 142 da CRFB, todavia, determina que as normas gerais a serem adotadas na organização, no preparo e no emprego das Forças Armadas deverão ser estabelecidas por lei complementar. Essas normas foram introduzidas no ordenamento jurídico brasileiro pela Lei Complementar n.ㅇ 97/99, que, com as alterações que Ihe foram dadas pela Lei Complementar n. 136/10, estabelece como atribuição subsidiária particular da Aeronáutica a de atuar contra todos os tipos de tráfego aéreo ilícito, especialmente no que se refere ao tráfico de drogas, armas, munições e passageiros ilegais (artigo 18, VII, Lei Complementar n.o 97/99). Portanto, a possibilidade da destruição de aeronaves hostis está fora do debate acerca da competência das Forças Armadas para a garantia da segurança pública.

${ }^{60}$ Ver o que já foi dito sobre o teor da decisão alemã no item 1.2.2.3, supra.
} 
pela violência que gera, mas também pelos danos à saúde da população que estão ligados ao consumo de substâncias entorpecentes. No quadro maior de uma política de repressão ao narcotráfico, todavia, uma medida como o abate de uma aeronave supostamente utilizada para transporte de drogas é inequivocamente desproporcional. Qual seria o impacto dessa medida tão grave na diminuição do volume de substâncias entorpecentes que circulam no Brasil? Dificilmente seria uma redução considerável: o narcotráfico é, como se sabe, um negócio extraordinariamente lucrativo, o que possibilita um grande dinamismo de suas operações. Se seus aviões forem interceptados, o transporte de drogas ainda pode ser feito por via fluvial (através dos rios da Amazônia) e, embora com maior possibilidade de controle pelas autoridades fronteiriças, por via terrestre (especialmente na divisa do Brasil com a Bolívia e o Paraguai).

Mesmo que assim não fosse, todavia, beira a ingenuidade acreditar que a destruição de alguns aviões poderia afetar significativamente a estrutura do tráfico internacional de drogas. As vidas dos pilotos das aeronaves seriam perdidas, mas essas pessoas não passam de meras "buchas de canhão" dos grandes barões do tráfico - os quais, obviamente, não arriscariam a própria pele em missões perigosas como essas. O controle das operações não seria afetado. Na outra ponta da cadeia, a demanda por substâncias entorpecentes continuaria a existir, garantindo a lucratividade das operações; ela dificilmente seria afetada por eventuais adaptações nos meios de transporte e distribuição dos produtos. ${ }^{61}$

Assim, pode-se dizer que, em atenção à primeira lei da ponderação, a medida de destruição da aeronave suspeita representa um prejuízo grave ao direito à vida dos tripulantes, ao mesmo tempo em que é capaz de fomentar apenas de forma leve ou mediana o princípio da segurança pública. No que se refere à classificação do prejuízo ao direito à vida, um argumento adicional pode ser extraído do artigo 5o, inciso XLVII, "a" da CRFB, que peremptoriamente veda a aplicação da pena de morte no território nacional em tempos de paz. Na prática, é inegável que o "tiro de destruição" acaba funcionando como a execução de uma sentença de morte contra as pessoas que estão a bordo da aeronave, uma sentença de morte "prolatada" sem qualquer processo prévio, a talante de uma autoridade específica (segundo o artigo 10 do Decreto n. 5.144/04, o Comandante da Aeronáutica, que exerce esse poder por delegação do Presidente da República). ${ }^{62}$

\footnotetext{
${ }^{61} \mathrm{Em}$ um horizonte mais amplo, pode-se afirmar que essas circunstâncias evidenciam o retumbante fracasso da política de "guerra às drogas". As autoridades brasileiras têm o dever, pois assim estabelece a legislação vigente no país, de coibir o narcotráfico, e vêm tentando fazê-lo através dos meios que lhe são juridicamente facultados; a eficácia dessas medidas de repressão ao tráfico, todavia, é profundamente duvidosa, e parece indiscutível que, como efeito colateral, elas vêm produzindo fendas maiores no abismo social brasileiro, com o agravamento de um quadro que, por si, já é desolador. A expressão "guerra às drogas", nesse contexto, acaba sendo um eufemismo para "guerra aos marginalizados", cujos resultados mais visíveis são o encarceramento em massa de pessoas pobres e o recrudescimento da violência nas favelas. Talvez a solução para esse grave problema não esteja no aumento da repressão, mas, ao contrário, na legalização de determinadas substâncias, que poderia ser um primeiro passo para afetar o poderio econômico do narcotráfico (ao qual, naturalmente, favorece a ilegalidade). Esse tema, contudo, é demasiadamente complexo e demandaria uma investigação à parte.

${ }^{62}$ A propósito, veja-se a lição de José Afonso da Silva: "Ao direito à vida contrapõe-se a pena de morte. Uma constituição que assegure o direito à vida incidirá em irremediável incoerência se admitir a pena de morte. É da tradição do Direito Constitucional brasileiro vedá-la, admitida só no caso de guerra externa declarada, nos termos do art. 84, XIX (art. 5ㅇ, XLVII, a), porque, aí, a Constituição tem que a sobrevivência da nacionalidade é um valor mais importante do que a vida individual de quem porventura venha a trair a pátria em momento cruciante." (SILVA, José Afonso da. Curso de Direito Constitucional Positivo. 32. ed. São Paulo: Malheiros, 2009. p. 201-202.)
} 
Também do ponto de vista da segunda lei da ponderação, a medida de destruição da aeronave revela-se desproporcional. Em termos de segurança empírica, a morte dos tripulantes da aeronave, caso efetivada a medida de destruição, é contígua à certeza. Por outro lado, o fato de se tratar de uma aeronave destinada ao tráfico de entorpecentes não pode, em muitos casos, ser demonstrado com a necessária medida de certeza; a possibilidade de que ela não seja uma aeronave hostil, mas que esteja meramente enfrentando um problema de comunicação, não pode ser de plano descartada. Tem-se, assim, um grau de insegurança empírica que não é compatível com uma intervenção tão intensa no direito fundamental em questão. ${ }^{63}$

Com base nessas considerações, pode-se dizer que o $\S 20$ do artigo 303 do CBA, com a redação que the foi dada pela Lei n.o 9.614/98, é incompatível com a ordem constitucional brasileira. A questão, todavia, não foi, até o presente momento, apreciada em sede de controle de constitucionalidade pelo Supremo Tribunal Federal, órgão ao qual compete a guarda da Constituição (artigo 102, caput, CRFB).

\section{- CONCLUSÃO}

As preocupações com a segurança do tráfego aéreo ganharam uma nova dimensão após os ataques terroristas de 11 de setembro de 2001. Esses fatos tiveram uma gigantesca repercussão no mundo inteiro, e na Alemanha não foi diferente: nesse país, a tendência de recrudescimento das medidas de segurança a bordo das aeronaves encontrou sua expressão mais visível na promulgação da Lei de Segurança Aérea.

No ano de 2006, contudo, o Tribunal Constitucional Federal alemão declarou inconstitucional o dispositivo da referida lei que previa a possibilidade de abate de aeronaves quando houvesse a suspeita de uma ameaça terrorista. Com essa decisão, deu-se primazia ao direito à vida e à garantia da dignidade humana das pessoas inocentes a bordo da aeronave sequestrada. Do ponto de vista da teoria da ponderação, os fundamentos da decisão podem ser expressos analiticamente por meio da fórmula peso, de modo a demonstrar que a insegurança empírica a respeito da efetiva existência de um atentado terrorista é um fator determinante para o resultado da ponderação efetuada pelo Tribunal Constitucional Federal.

No Brasil, aeronaves supostamente utilizadas para tráfico de drogas são, por lei, classificadas como hostis e podem ser alvo de destruição. Em que pese a ausência de qualquer discussão a respeito da constitucionalidade da matéria no âmbito do Supremo Tribunal Federal, é possível afirmar que, quando analisada através do instrumental fornecido pela teoria da ponderação, a medida não se harmoniza com a ordem constitucional brasileira.

\footnotetext{
${ }^{63}$ Seja lembrado que a insegurança empírica desempenhou um papel decisivo na decisão alemã (ver item 1.2.2.3, supra).
} 


\section{REFERÊNCIAS}

ALEXY, Robert. A Fórmula Peso. in: Idem. Constitucionalismo Discursivo. Tradução de Luís Afonso Heck. 4. ed. Porto Alegre: Livraria do Advogado, 2015.

. Direito Constitucional e Direito Ordinário - Jurisdição Constitucional e Jurisdição Especializada. in: Idem. Constitucionalismo Discursivo. Tradução de Luís Afonso Heck. 4. ed. Porto Alegre: Livraria do Advogado, 2015.

. Direitos Fundamentais, Ponderação e Racionalidade. in: Idem. Constitucionalismo Discursivo. Tradução de Luís Afonso Heck. 4. ed. Porto Alegre: Livraria do Advogado, 2015.

. Theorie der Grundrechte. 2. Aufl. Frankfurt am Main: Suhrkamp, 1994.

. Theorie der Juristischen Argumentation: die Theorie des Rationalen Diskurses als Theorie der Juristischen Begründung. 2. Aufl. Frankfurt am Main: Suhrkamp, 1991.

KLATT, Matthias; SCHMIDT, Johannes. Espaços no Direito Público: Para a Doutrina da Ponderação da Teoria dos Princípios. Tradução de Luís Afonso Heck. Porto Alegre: Sergio Antonio Fabris, 2015.

LUDWIG, Roberto José. A Norma de Direito Fundamental Associada: Direito, Moral, Política e Razão em Robert Alexy. Porto Alegre: Sergio Antonio Fabris, 2014.

SILVA, José Afonso da. Curso de Direito Constitucional Positivo. 32. ed. São Paulo: Malheiros, 2009.

TREVISAN, Leonardo Simchen. Ponderação, Argumentação, Racionalidade: Robert Alexy e Seus Críticos. Porto Alegre: Sergio Antonio Fabris, 2017. 